\title{
Support Vector Machine Model to Select Exterior Materials
}

\author{
Kim, Sangyong* \\ School of Construction Management and Engineering, University of Reading, Reading, RG6 6AW, UK
}

\begin{abstract}
Choosing the best-performance materials is a crucial task for the successful completion of a project in the construction field. In general, the process of material selection is performed through the use of information by a highly experienced expert and the purchasing agent, without the assistance of logical decision-making techniques. For this reason, the construction field has considered various artificial intelligence (AI) techniques to support decision systems as their own selection method. This study proposes the application of a systematic and efficient support vector machine (SVM) model to select optimal exterior materials. The dataset of the study is 120 completed construction projects in South Korea. A total of 8 input determinants were identified and verified from the literature review and interviews with experts. Using data classification and normalization, these 120 sets were divided into 3 groups, and then 5 binary classification models were constructed in a one-against-all (OAA) multi classification method. The SVM model, based on the kernel radical basis function, yielded a prediction accuracy rate of $87.5 \%$. This study indicates that the SVM model appears to be feasible as a decision support system for selecting an optimal construction method.
\end{abstract}

Keywords : exterior material, one-against-all, support vector machine

\section{Introduction}

Materials account for a very large percentage of building costs. More than 50 60\% of total cost of project has spent on the work relevant to materials [1]. In the past, the material process is a simple task in which limited conventional materials, such as stone and brick, of selecting materials, are considered. However, the rapid developments of construction method and raw materials have transmuted the skin of buildings sharply. According to Farag[2], about 4,000 metallic alloys and over

\section{Received : February 6, 2011}

Revision received : May 25, 2011

Accepted : May 30, 2011

* Corresponding author: Kim, Sangyong

[Tel: 44-118-378-7182, E-mail: rd026992@reading.ac.uk]

(c)2011 The Korea Institute of Building Construction, All rights reserved.
5,000 numbers of plastic, ceramics, glasses have been used in the material market in construction field. For this reason, designers and engineers often face the problems of selecting materials from vast alternatives with consideration of building constraints [3].

In general, the material work at early stage is concerned with core information of project, such as duration, structure type, design and cost, to determine the quality of overall building [4,5]. Additionally, material selection has affected the environment, lead to greenhouse emissions via their careless exploitation and transportation [6]. As such, this process is a crucial topic in construction work scope. In spite of the gravity of selecting materials, the process of selecting materials is often neglected in work process and considered by the purchasing agent when assessing total cost of project [7]. The 
reason is that selection of the best-performance materials is a complex task due to the vast range of considerations: environmental impact, design suitability and changing of total cost [3]. For this reason, the selection of a material method is nearly based on opinion from highly experienced practitioner, who has scope to deal with the extensive material expertise relevant to project. However, such illogical decision-making or passive process could have negative effect on the entire project. The inappropriate selection of materials prior to construction can contribute to decrease quality and completion degree of project. Therefore, considering that construction field needs supporting systems with their own material selection methods.

In order to escape such a rule of thumbs of the construction method, Artificial intelligence (AI) techniques are widely used as a support application to assist engineers' decision making by conducting a great deal of study in construction industry over the past few decades [8]. For instance, at early stage of project, the construction cost estimates, which is influenced by a wide range of factors, has been assessed by various AI techniques. Especially, artificial neural network (ANN), adaptive boosting algorithms (AdaBoost) and case-based reasoning (CBR) have been regarded as a representative technique of AI in construction process [9].

Although such applications of AI techniques are popular in the construction field as support programs, they still have limitations like the lack of self-learning and time consumption mechanism [10]. ANN is one of the AI techniques to predict [10], classify [11] and select approximate data [12] in construction field. However, ANN requires higher trial and error processing time in order to structure network due to the fact that ANN basically depends on liner regression so that it is not appreciate when applying non-liner relationships [13]. In terms of Adaboost, recently, it is a notable classifier because of its effective feature selection, generalization performance and low computational costs [14]. Still, it has demerit that every feature leads to one decision so that dependencies between features cannot be utilized well even though it provides a successful learning algorithm and has strong boundary of generalization [15]. CBR is an alternative to an expert system, which relies on rule-based reasoning. CBR has limitation to reflect suitable current criteria to index and match due to depending on previous experience without validating it in the new situation [16]. This is an apparent problem in changing property of object that past cases may not reflect current object trends.

Among recent AI techniques, SVM has received attention due to its excellent capacity for self-learning and generalization performance in comparison to other AI techniques [17]. In particular, the function of SVM generalization and classification is sharply better than previous techniques by simultaneously determining the problems of two classes [18]. Existing AI techniques need various factors to calculate for optimal function through trial and error with a higher process time. Such complicated algorithm process is not suitable to deal with the wide range of data in spelling over the varieties inside given classes. However, SVM is able to detect the optimal function through via the nonlinear mapping of input vectors into a higher dimension feature space (kernels), without any knowledge of the mapping [19]. Thus, SVM has been shown higher performance to solve large sample size problems in comparison to conventional AI techniques with minimizing running time [20]. For this reason, it can be applied to practice fields such as human face detection [17], nonlinear time series predictions [21] and dynamic reconstruction of a chaotic system [22].

This study proposes the application of a systematic and efficient model to support process of selecting 
exterior material of the building. Firstly, the theory of SVM is briefly reviewed. The potential of SVM model is presented and demonstrated by applying a real data set from South Korea construction market in next chapter, and then the results of proposed SVM model are evaluated with output data obtained from ANN and CBR in "Result". Finally, conclusions and suggestions for further study are presented.

\section{Support Vector Machine}

\subsection{SVM Approach}

The SVM has been developed principally by Vanpik and his collaboration at Bell Laboratories in 1992 [23]. The principle of SVM is based on statistical learning theory and the structural risk minimization, which has shown to deliver higher performance than traditional empirical risk minimization used by many of the learning machines [17]. The SVM is originally designed for binary classification in order to construct an optimal hyper-plane so that the margin of separation between two classes, negative and positive, could be maximized [24]. If the data are linearly separated, SVM can trains liner machines to estimate optimal hyper-plane for separating the data without error into the maximum distance between the hyper-plane and the nearest target points. In terms of non-linear case, SVM provides classification boundary via specific nonlinear mapping the input vectors into high dimensional space. In this sense, the SVM has advantages including strong inference capacity, greater generalization ability and less learning time compared to the other learning techniques [22].

\subsection{Theory of SVM}

Consider the problem of separating the set of training set $\left\{\left(x_{i}, y_{i}\right)\right\}_{i=1}^{l}$, where $x_{i} \in \mathrm{R}^{d}$ is the $i$ th input vector and $y_{i} \in\{-1,1\}, i=1, \cdots, 1$ is the associated label, with $y_{i}=1$ for class 1 (positive value), and $y_{i}=-1$ (negative value) for class 2. According to Vapnik[23] the separate hyper-plane, which separates the training datum linearly, can be formulated as

$$
y_{i}\left(x_{i} \cdot w+b\right) \geq 1 \quad i=1,2, \cdots, 1
$$

Where a specific pair $(w, b)$ is inner product of two vectors; $w=$ weight vector to the hyper-plane that separates the positive value from the negative cases; and $b$-scalar. For the case a two-dimensional input space as shown Fig. 1(a), there are many possible liner classifiers that can separate the data. However, there is only one maximum "margin" that is the distance between the separating hyper-plane and the training datum, the nearest to the hyper-plane. This linear classifier is termed the optimal hyper-plane. The SVM training aims to find the linear separating hyper-plane that gives the maximum margin between two hyper-planes $\left(x_{i} \cdot w^{+b}-1=0\right.$ and $\left.x_{i} \cdot w+b+1=0\right)$ in order to maximize generalization performance. The margin of separation between two classes can be shown to be one that minimizes the functional according to Cristianini and Shawe-Tayler [25]:

$$
\text { Minimize } \Phi(w)=\frac{\left\|w^{2}\right\|}{2}
$$

where the cost function $\Phi(w)$ is a convex function of $W$ and the constraints are linear in $w$. This optimization problem can be switched to a Lagrangian formulation [26] as follow:

$$
\text { Maximize } L_{p}=\frac{1}{2} w \cdot w-\sum_{i=1}^{i} \alpha_{i}\left[y_{i}\left(w \cdot x_{i}-b\right)-1\right]
$$

Subject to $\sum_{i=1}^{i} \alpha_{i} y_{i}=0$ and $\alpha_{i} \geq 0, \quad i=1,2 \cdots, 1$

The objective function $L_{p}$ and aiding non-negative variables $\alpha$ are the Lagrange Multiplier, and then the $w$ could be stated 


$$
w=\sum_{i=1}^{i} \alpha_{i} y_{i} x_{i}
$$

In addition, the optimal hyper-plane can be formulated by Kühn-Tucker theorem as follow:

$$
i=1, k, 1
$$

If points $x_{i}$ are not located on hyper-plane, $\alpha_{i}=0$ must be satisfied. Those points $x_{i}$ are called the "support vector". Therefore, Eq(5) can be re-defined

$$
w=\sum_{\substack{\text { support } \\ \text { vecoror }}} \alpha_{i} y_{i} x_{i}
$$

In this sense, the optimal hyper-plane is located on a linear combination of the support vectors.

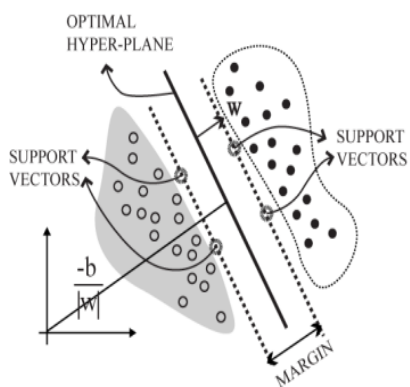

(a)

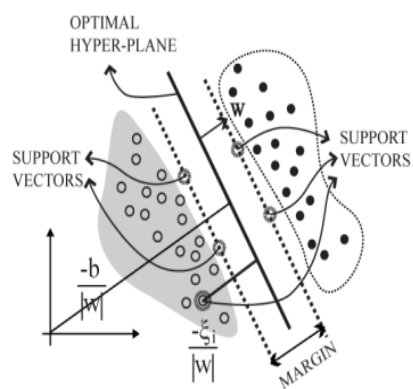

(b)
Figure 1. Optional separating hyper-plane [19]

In terms of non-separable data, SVM is applied by introducing a new positive slack variables $\zeta$, $(i=1, \ldots, N)$ in order to be sufficiently tolerant of classification errors, as shown in Fig. 2(b). It can be rearranged to Eq. (1) as follow:

$$
y_{i}\left(x_{i} \cdot w+b\right) \geq 1-\xi_{i}, \quad i=1, k, 1
$$

To obtain the optimal separating hyper-plane, it can be expressed as follow:

$$
\text { Minimize } L(w, \xi)=\frac{1}{2} w \cdot w-C\left(\sum_{i=1}^{i} \xi_{i}\right)
$$

where $C$-user-specified parameter that controls trade-off between the complexity model and the minimization of the classification error.

In the case where the decision function is not a linear function of the data, the SVM can map the input vectors $X \in R^{d}$ into a high dimensional space, where is called as the feature space (Fig. 2), $Z$ via nonlinear mapping $\Phi: R^{d} \rightarrow R^{d}(D \gg d)$. Thus, this quadratic optimization problem can be solved by maximizing the quadratic form

$$
L_{D}=\sum_{i=1}^{l} \alpha_{i}-\frac{1}{2} \sum_{i, j=1}^{l} \alpha_{i} \alpha_{j} y_{i} y_{j} K\left(x_{i} \cdot x_{j}\right)
$$

where $K\left(x_{i} \cdot x_{j}\right)$ is kernel function. It is dispensable to deal with the feature space, reduce the amount of consumption and straightforwardly extend feature space. A kernel function should follow this condition known as the function satisfying Mercer' s thermo (Mercer, 1909).

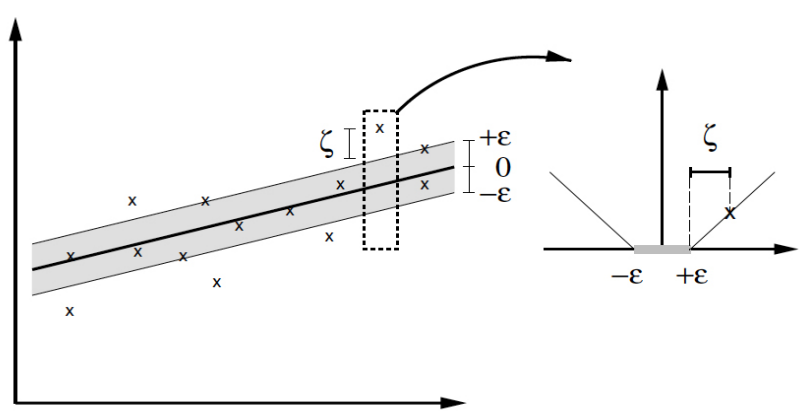

Figure 2. Desired accuracy $\varepsilon$ and slack variable $\xi$ [23]

In order to solve equation determinants of Lagrange multipliers and implement the optimal separating hyper-plane in the feature space is given by

$$
f(x)=\operatorname{sgn}\left(\sum_{i=1}^{l} y_{i} \alpha^{0} K\left(x_{i} \cdot x\right)+b_{0}\right)
$$

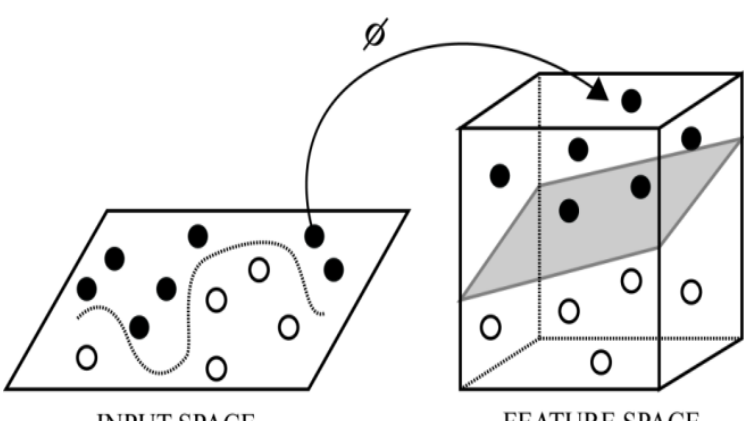

INPUT SPACE

FEATURE SPACE

Figure 3. Mapping input data into the feature space [28] 
Consequently, everything has been described about the linear is applied to nonlinear cases by using a suitable kernel $K$ instead of the dot product (Fig. 3). The SV algorithm can construct a variety of learning machines by using different kernel functions (Fig. 4), some of which coincide with classical architectures.

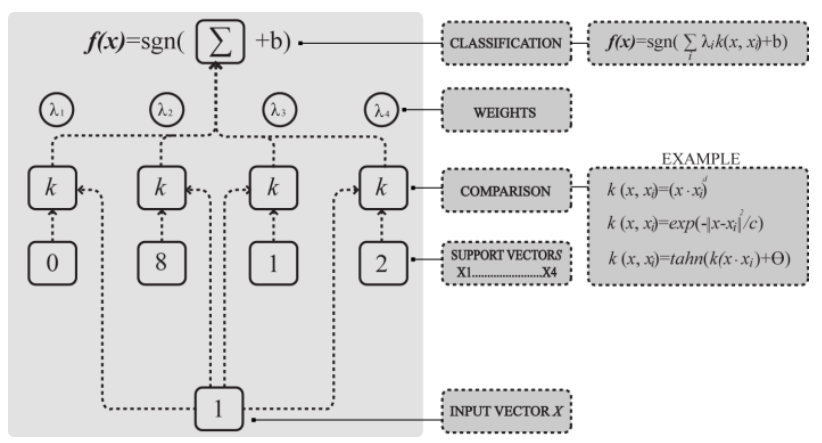

Figure 4. Architecture of SVM

Generally, three kinds of function have been used among other providing acceptable kernels. Respective kernel functions are described as follows:

$$
\text { Polynominal kernel: } \quad K\left(x_{i} \cdot x_{j}\right)=\left(x_{i} \cdot x_{j}+1\right)^{n}
$$

where the degree of the polynominal $n$ is user-defended value.

- Radical basis function: $K\left(x_{i} \cdot x_{j}\right)=\exp \left(-\gamma\left\|\left(x_{i} \cdot x_{j}\right)\right\|^{2}\right)$ (12)

Where $\gamma$ is user-defined value.

- Two-layer neural networks (Sigmodi):

$$
K\left(x_{i} \cdot x_{j}\right)=\operatorname{than}\left(k x_{i} \cdot x_{j}-\delta\right)^{\mathrm{n}}
$$

where $k$ and $\delta$ are user-defined value.

\section{Datasets Construct}

\subsection{Determinants for selection of finishing materials}

Basically, the variables to use for selecting exterior materials were determined in two steps in this study. The variables candidates to influence the selecting material were initially made by reviewing previous studies $[3,5,7,29,30]$. In second step, selected factors were verified and evaluated via interviewing seventeen experts who have been highly experienced practitioners in the construction field in South Korea. Consequently, eight factors for selecting an exterior material were determined. Table 1 shows an outcome of determinants for Selection of Materials. In terms of total cost is converted based on Building Cost Index (BCI) in 2005.

\begin{tabular}{|c|c|c|c|}
\hline \multirow{2}{*}{ Factor } & \multirow{2}{*}{ Type of factor } & \multicolumn{2}{|c|}{ Remarks } \\
\hline & & Max. & Min. \\
\hline Location & Nominal & \multicolumn{2}{|c|}{ Seoul, Daejun, Busan } \\
\hline Site area $\left(\mathrm{m}^{2}\right)$ & Numerical & 151,134 & 2,912 \\
\hline No. of story(EA) & Numerical & 45 & 9 \\
\hline Structure system & Nominal & \multicolumn{2}{|c|}{$\mathrm{RC}, \mathrm{SRC}$} \\
\hline Gross area $\left(1,000 \mathrm{~m}^{2}\right)$ & Numerical & 497,677 & 3,078 \\
\hline Duration(months) & Numerical & 75 & 12 \\
\hline Total cost(1,000won) & Numerical & $497,041,815$ & 851,300 \\
\hline Material $\operatorname{cost}\left(\right.$ won $\left./ \mathrm{m}^{2}\right)$ & Numerical & 350,000 & 165,000 \\
\hline
\end{tabular}

Table 1. Determinants of materials (input variables)

The outcomes of input variables were normalized for controlling the number of group size and applying SVM model. The outcome of input variables was re-coded in the range of " 0 " to " 1 " due to the fact that the range of gross area outcome is comprehensive in comparison with the story of building or the duration of construction [31]. In terms of text variable, such as structure system, sorted by the number of type in the same scope (e.g, RC:1, SRC:0).

\subsection{Data construction}

The 120 completed construction projects in urban areas of South Korea were collected from well-known companies. The boundary of dataset was limited to exterior materials within apartment during the period from 2000 to 2008. In order to carry out SVM model, collected data is split into three sets in 
the ratio 66\% (Training set), 17\% (Validation set) and $17 \%$ (Test set) via random selection. "Training set" is consisted of water paint (32EA), aluminum panel (31EA), stainless panel (8EA), granite (7EA) and wood panel (2EA) according to the number of selected material in data. The results of selecting materials were classified into 5 classes: Water paint, Al panel, Stainless panel, Granite, Wood panel, which are representative used material on construction site, as shown in Table 2.

Table 2. Composition of dataset

\begin{tabular}{ccccc}
\hline Class & No. & Training & Validation & Test \\
\hline Water Paint & 50 & 32 & 9 & 9 \\
Aluminum Panel & 43 & 31 & 6 & 6 \\
Stainless Panel & 12 & 8 & 2 & 2 \\
Granite & 11 & 7 & 2 & 2 \\
Wood panel & 4 & 2 & 1 & 1 \\
Total & 120 & 80 & 20 & 20 \\
\hline
\end{tabular}

\subsection{SVM for selecting material}

\subsubsection{One-Against-All (OAA)}

In this study, the SVM model was created by SVMdark [32] which is based on SVMlight version [33]. SVM model was applied to real data sets for selecting exterior material in "Test set" . Originally, SVM was designed for binary classification (2 classes) but cannot naturally extend to more than two classes. However, given data (selected material in cases) was divided into 5 classes. To escape this problem, the SVM model needs to be extended for multiple classifications. "One-Against-All (OAA)" and "Pairwise" have been used as conventional ways to extend the SVM model for multiple scenarios [24]. In both ways, the OAA classific ation method is the earliest and one of most widely used implementations [34]. For this reason, this study constructs the SVM model on the OAA method. The OAA principle is as follow:

In the SVM, suppose the $i^{\text {th }}$ decision function, with the maximum margin, that classifies class $i$ and the remaining classes be formulated

$$
D_{i}(x)=w_{i}^{t} x+b_{i}
$$

where $w_{i}$ is the $m$-dimensional vector and $b_{i}$ is a scalar.

The hyperplane $D_{i}(x)=0$ forms the optimal separating hyperplane and, if the training data are linearly separable, $D_{1}(x)=1$ and those belonging to the remaining classes satisfy $D_{1}(x)=-1$. For the conventional SVM, if for the input vector $x$

$$
D_{i}(x)>0
$$

\subsubsection{Proposed classification model}

In order to classify 5 classes, the SVM model could be extended according to the OAA classification method as mentioned above. This study has proposed four Binary Classifications (BC) to apply the SVM model. At the Class 1 BC, Class 1 and rest class (Class 2 to Class 5) were grouped, Class 1 belongs to the positive set (target value: +1 ) and four classes belong negative set (target value: -1). Along the same way, the rest Classes were grouped in series. The proposed classification model was designed to preferentially select material which is often used in the given cases. Thus, each classification (Class 1 to Class 5) can group into water paint, aluminum panel, stainless panel, granite and wood panel in order.

\section{Result}

In order to structure SVM model, optimal kernel function and related hyper-parameters need to be determined respectively in the regression part of the SVMdark. $5 \mathrm{BC}$ are tested in four kernel functions: linear, polynominal, radical basis and sigmoid. The result of preliminary tests showed that a polynominal function was chosen as the optimal kernel function, 
which showed the lowest Mean Squared Error, for discrete BC. Then the hyper-parameters that contribute to the best performance in SVM model are determined. Table 3 shows the best kernel functions and hyper-parameters in respective $\mathrm{BC}$ by the regression process with 50 runs in SVMdark.

Table 3. Output of optimal parameters for respective binary classifiers

\begin{tabular}{ccccc}
\hline Model & Kernel & D & S & C \\
\hline Water Paint-BC & Polynominal & 2 & 3 & 2 \\
Aluminum panel-BC & Polynominal & 3 & 1 & 4 \\
Stainless panel-BC & Polynominal & 2 & 1 & 2 \\
Granite-BC & Polynominal & 5 & 1 & 5 \\
Wood panel-BC & Polynominal & 4 & 1 & 3 \\
\hline
\end{tabular}

Note. D: Number of degree; S: Sines; C: Cosines

Table 4. Comparison of result with actual dataset (Fold 1)

\begin{tabular}{|c|c|c|c|c|c|c|}
\hline Objective & $\begin{array}{l}\text { WP- } \\
\mathrm{BC}\end{array}$ & $\begin{array}{l}\mathrm{AP}- \\
\mathrm{BC}\end{array}$ & $\begin{array}{l}\mathrm{SP}- \\
\mathrm{BC} \\
\end{array}$ & $\begin{array}{c}\mathrm{Gr}-\mathrm{B} \\
\mathrm{C}\end{array}$ & $\begin{array}{l}\text { WDP } \\
-B C \\
\end{array}$ & Result \\
\hline $\begin{array}{l}\text { Water } \\
\text { Paint }\end{array}$ & 1.08 & -1.14 & -2.81 & -0.85 & -5.71 & Water Paint \\
\hline $\begin{array}{l}\text { Water } \\
\text { Paint }\end{array}$ & 1.14 & -1.12 & -5.10 & -0.98 & -4.99 & Water Paint \\
\hline $\begin{array}{l}\text { Water } \\
\text { Paint }\end{array}$ & 0.98 & -1.11 & -3.38 & -1.09 & -5.49 & Water Paint \\
\hline $\begin{array}{l}\text { Water } \\
\text { Paint }\end{array}$ & 1.03 & -0.18 & -2.99 & -1.41 & -5.78 & Water Paint \\
\hline $\begin{array}{l}\text { Water } \\
\text { Paint }\end{array}$ & 1.25 & -1.09 & -2.87 & -1.68 & -5.83 & Water Paint \\
\hline $\begin{array}{l}\text { Water } \\
\text { Paint }\end{array}$ & 1.28 & -1.18 & -2.87 & -1.78 & -5.79 & Water Paint \\
\hline $\begin{array}{l}\text { Water } \\
\text { Paint }\end{array}$ & 1.02 & -1.00 & -2.91 & -0.84 & -5.92 & Water Paint \\
\hline $\begin{array}{l}\text { Water } \\
\text { Paint }\end{array}$ & 0.99 & -0.97 & -3.49 & -1.00 & -5.96 & Water Paint \\
\hline $\begin{array}{l}\text { Water } \\
\text { Paint } \\
\end{array}$ & 1.11 & -0.88 & -3.40 & -0.83 & -6.00 & Water Paint \\
\hline $\begin{array}{l}\text { Aluminum } \\
\text { Pnl }\end{array}$ & -1.15 & 1.52 & -0.98 & -0.05 & -5.30 & $\begin{array}{l}\text { Aluminum } \\
\text { Pnl }\end{array}$ \\
\hline $\begin{array}{l}\text { Aluminum } \\
\text { Pnl }\end{array}$ & -1.02 & 0.96 & -3.67 & -0.62 & -3.89 & $\begin{array}{l}\text { Aluminum } \\
\text { Pnl }\end{array}$ \\
\hline $\begin{array}{l}\text { Aluminum } \\
\text { Pnl }\end{array}$ & -1.02 & 1.07 & -2.91 & -0.53 & -3.92 & $\begin{array}{l}\text { Aluminum } \\
\text { Pnl }\end{array}$ \\
\hline $\begin{array}{l}\text { Aluminum } \\
\text { Pnl }\end{array}$ & -1.17 & 1.21 & -3.30 & -0.82 & -5.03 & $\begin{array}{l}\text { Aluminum } \\
\text { Pnl }\end{array}$ \\
\hline $\begin{array}{c}\text { Aluminum } \\
\text { Pnl }\end{array}$ & -1.84 & -2.99 & -1.00 & 3.22 & -5.05 & Granite \\
\hline $\begin{array}{c}\text { Aluminum } \\
\text { Pnl }\end{array}$ & -1.39 & 1.56 & -1.22 & -1.42 & -5.14 & $\begin{array}{c}\text { Aluminum } \\
\text { Pnl } \\
\end{array}$ \\
\hline $\begin{array}{c}\text { Stainless } \\
\text { Pnl }\end{array}$ & -3.44 & -1.32 & 0.37 & -2.13 & -4.00 & $\begin{array}{c}\text { Stainless } \\
\text { Pnl }\end{array}$ \\
\hline $\begin{array}{c}\text { Stainless } \\
\text { Pnl }\end{array}$ & -4.14 & -1.83 & -0.87 & -0.92 & 1.34 & Wood Pnl \\
\hline $\begin{array}{l}\text { Granite } \\
\text { Granite } \\
\end{array}$ & $\begin{array}{l}-5.97 \\
-5.99 \\
\end{array}$ & $\begin{array}{l}-7.3 \\
-7.4 \\
\end{array}$ & $\begin{array}{l}-2.42 \\
-2.34 \\
\end{array}$ & $\begin{array}{c}0.07 \\
-0.32 \\
\end{array}$ & $\begin{array}{l}-2.60 \\
3.04 \\
\end{array}$ & $\begin{array}{c}\text { Granite } \\
\text { Wood Pnl }\end{array}$ \\
\hline Wood Pnl & -9.12 & $\begin{array}{c}-20.3 \\
6 \\
\end{array}$ & -2.36 & -1.39 & 1.49 & Wood Pnl \\
\hline
\end{tabular}

Note. Grey hatch : no matched result

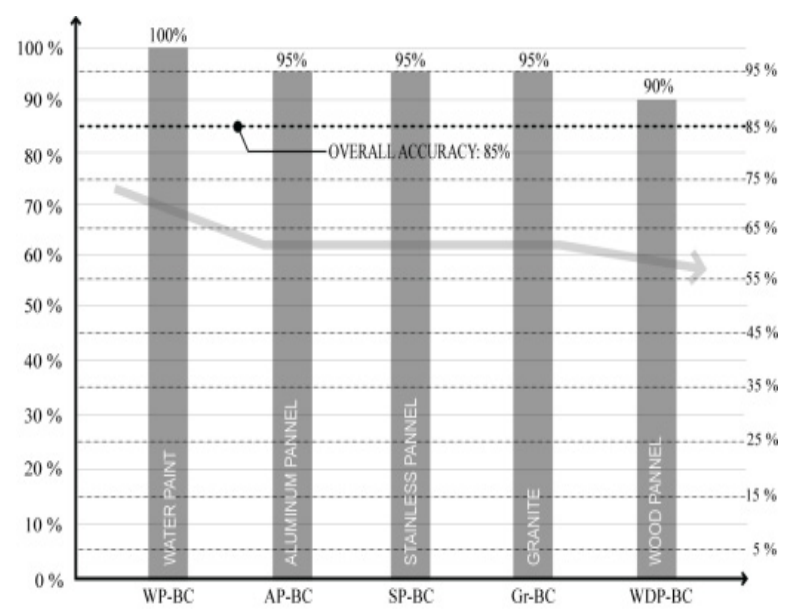

Figure 5. Accuracy of respective binary classifiers (Fold 1)

In classification part of SVMdark, determined kernel functions and hyper-parameters are used to select exterior material in dataset. For example, the results of fold 1 reported in Table 4. The accuracy was measured by the percentage of matching correctly classified in 5 BC. The overall accuracy of the SVM model was $85 \%$ in training data (fold 1). In terms of respective $\mathrm{BC}$, the prediction performance of 5 classifications was slightly different. Water Paint (WP)-BC ranked first with $100 \%$ in total classifications. The lowest rank was occupied by Wood Panel (WDP)-BC, rest classifications (Aluminum Panel, Stainless Panel and Granite classification) were 95\% as same position. The result showed that WP-BC superiorly performs compared to other $\mathrm{BC}$ in dataset, are given in Fig. 5. Consequently, $\mathrm{WP}-\mathrm{BC}$ and $\mathrm{AP}-\mathrm{BC}$, which relatively have a great deal of cases, have shown the higher accuracy than WDP-BC formed small case in the given data. The number of case can influence on the accuracy of respective $\mathrm{BC}$ in the decision making process. Thus, it can be expected that the overall accuracy percentage of $\mathrm{BC}$ will be improved with increasing the number of input data in respective class. 
Table 5. Result of six-fold cross-validation

\begin{tabular}{ccccccc}
\hline Experiment & Fold 1 & Fold 2 & Fold 3 & Fold 4 & Fold 5 & Fold 6 \\
\hline $\begin{array}{c}\text { Number of } \\
\text { incorrect } \\
\text { cases }\end{array}$ & 3 & 3 & 4 & 1 & 2 & 2 \\
$\begin{array}{c}\text { Accuracy } \\
\text { rate }(\%)\end{array}$ & 85 & 85 & 80 & 95 & 90 & 90 \\
\hline
\end{tabular}

The classification results of $5 \mathrm{BC}$ were compared with the actual result in datasets to evaluate the performance of the SVM model, $k$-fold cross-validation was also adopted using the same hyperparameter of the polynomial function. Table 5 shows the results of siX-fold cross-validation to evaluate the performance of the SVM model. Overall, the average accuracy was $87.5 \%$, with a minimum of $80 \%$ and a maximum of $95 \%$.

In these respects, SVM, which has simple process to construct various parameters, model could be verified as a superior technique to select material.

\section{Conclusion}

This study has proposed a new model for selecting exterior material based on the SVM in order to examine the applicability and potential of SVM in construction field. In the experiment, actual case data from 120 completed projects in South Korea was divided into five classes with normalizing process to carry out the SVM model; and arranged respective classes were used for constructing $\mathrm{BC}$ on OAA classification method. In addition, the SVM model showed higher performance to determine parameters with the less processing time. These results demonstrated that the SVM model could be assistance for decision maker to select high-performance material in construction field. In the future, the SVM can serve as a technique for determining optimal construction method in company know-how system, at early stage.

Likewise, SVM model in this study showed validation and potential to apply in construction field. Further study, still, is necessary to improve SVM model for application to practical field. As mentioned above, the accuracy of SVM model is affected by the number of cases in dataset so that further study will carry out in more than 120 dataset in order to expect higher accurate. In addition to this data supplementation, the statistical verification will be proposed to determine crucial factors considered in selecting materials. Such considerations will make SVM superiorly come up to construction field.

\section{References}

1. Construction Industry Institute (CII). Procurement and materials management: a guide to effective project execution. New York(US): University of Texas at Austin; 1999. 176. p

2. Farag MM. Quantitive method of material selction. Handbook of materials selection. New York (US): Wiley; 2007. 1520. p

3. Sefair JA, Castro-Lacouture D, Medaglia AL. Material selection in building construction using optimal scoring method (OSM). In: Samuel T, Ariaratnam, Rojas EM, editors; In Proceedings of the 2009 Construction Research Congress; Seattle. Washington: ASCE; 2009 April. 1079-86.

4. Amen R, Vomacka P. Case-based reasoning as a tool for materials selection. Material and Design 2001 Aug;21(5):353-8.

5. Jang H, Lee S, Choi S. Optimization of floor-level construction material-layout using genetic algorithms. Automation in Construction 2007 July;16(4):531-45.

6. Ries R, Bilec M, Gokhan NM, Needy KL. The economic benefits of green buildings: a comprehensive case study. The Engineering Economist. 2006 Sept;51(3):259-95.

7. Formoso CT, Revelo VH. Improving the materials supply chains system in small-sized building firms. Automation in Construction 1999 Aug;8(6):663-70.

8. An SH, Park UY, Kang KI, Cho MY, Cho HH. Application of support vector machine in assessing conceptual cost estimates. Journal of Computing in Civil Engineering 2007 July;21(4):259-64.

9. Akintoye A, Fitzgerald E. A survey of current cost estimating practices in the UK. Construction Management and 
Economics $2000 \mathrm{Mar} ; 18(2): 161-72$.

10. Huang Z, Chen H, Hsu CJ, Chen WH, Wu S. Credit rating analysis with support vector machines and neural networks: a market comparative study. Decision Support System 2004 Sept;37(4):543-58.

11. Roy A, Barat P, De SK. Material classification through neural network. Ultrasonics 1995 May;33(3):175-80.

12. Alsugair AM, Al-Qudrah AA. Artificial neural network approach for pavement maintenance. Journal of Computing in Civil Engineering 1998 Oct;12(4):249-55.

13. Kumar PR, Ravi V. Bankruptcy prediction in banks and firms via statistical and intelligent techniques- a review. European Journal of Operational Research 2007 July;180(1):1-28.

14. Shin YS, Kim DW, Kim JY, Kang KI, Cho MY, Cho HH, Application of adaboost to the retaining wall method selection in construction. Journal of Computing in Civil Engineering 2009 May;23(3):188-92.

15. Nunn C, Kummert A, Muller D, Meuter M, Muller-Schneiders S. An improved adaboost learning scheme using LDA features for object recognition. Intelligent Transportation Systems 2009 ITSC 09 12th International IEEE Conference on; St. Louis: IEEE Conference Proceedings; 2009 January. p.1-6.

16. Kolodner $\mathrm{L}$. An introduction to case-based reasoning. Artificial Intelligence Review 1992;6(1):3-34.

17. Osuna E, Freund R, Girosi F. Training support vector machines: an application to face detection. CVPR '97 Proceedings of the 1997 Conference on Computer Vision and Pattern Recognition; Washington, D.C; IEEE Computer Society; 1997 Jan. p. 130-6.

18. Dibike YB, Velickov S, Solomantine D, Abbott MB. Model induction with support vector machines: induction and applications, Journal of Computing in Civil Engineering 2001 July;15(3):208-16.

19. Burges CJC. A tutorial on support vector machines for pattern recognition. Data Mining and Knowledge Discovery 1998 June;2(2):121-67.

20. Steinwart I. Support vector machines are universally consistent, Journal of Complexity 2002 Sept;18(3):768-91.

21. Muller KR, Smola A, Ratsch G, Scholkopf B, Kohlmorgen J, Vapnik V. Predicting time series with support vector machines, ICANN '97 Proceedings of the 7th International Conference on Artificial Neural Networks 1997; London (UK); 1997. p. 99-1004.
22. Mattera D, Haykin S. Support vector machines for dynamic reconstruction of a chaotic system. Advances in Kernel Methods. Massachusetts (MA): MIT Press Cambridge; 1999. p. 211-42.

23. Vapnik V. The nature of statistical learning theory. 2nd Ed. New York: Springer; 1995. p. 1-314

24. Abe S. Analysis of multiclass support vector machines. In Proceeding of International Conference on Computational Intelligence for Modelling Control and Automation 2003; Vienna (Austria); CIMCA; 2003. p.385-96.

25. Cristianini N, Shawe-Tayler J. An introduction to support vector machine and other kernel-based learning methods. 1st Ed. Cambridge (UK): Cambridge university press; 2000. p. 1-204.

26. Bertsekas DP. Constrained optimization and Lagrange multiplier methods. 1st Ed. Sandiego (CA): Athena Scientific; 1996. p. 1-410.

27. Mercer T. Functions of positive and negative type and their connection with the theory of integral equations. Philosophical Transactions of the Royal Society: Reference. 1909 Jan;209:415-46.

28. Kim KJ. Finanacial time series forecasting using support vector machines, Neurocomputing 2003 Sept;55(1):307-19.

29. Ullah AMMS, Khalifa HH. An intelligent method for selecting optimal materials and its application. Advanced Engineering Informatics. 2008 Oct;22(4):473-83.

30. Athanasopoulos G, Riba CR, Athanasopoulou C. A decision support system for coating selection based on fuzzy logic and multi-criteria decision making. Expert Systems with Applications 2009 Oct;36(8):10848-53.

31. Park UY, Kim GH. A study on predicting construction cost of apartment projects based on Support Vector Regression at the Early Project Stage. Journal of the Architectural Institute of Korea Planning and Design 2007 April;23(4):165-72. Korean.

32. Sewell M. SVMdark: A Windows implementation of a support vector machine. London (UK): UCL; 2005.

33. Joachims T. Making large-scale SVM learning practical. Support Vector Learning. Massachusetts (MA): MIT Press Cambridge; 1999. p. 41-56.

34. Weston J. Watkins C. Support vector machines for multi-class pattern recognition. In Proceeding European Symposium on Artificial Neural Networks 1999. Bruges (Belgium): ESANN; 1999. p. 219-24. 